\title{
Chronic obstructive pulmonary disease phenotypes: imprint on pharmacological and non-pharmacological therapy
}

\author{
Mostafa Bakeer ${ }^{1,2}$, Georg-Christian Funk ${ }^{2}$, Arschang Valipour ${ }^{2}$ \\ ${ }^{1}$ Chest Medicine Department, Faculty of Medicine, Mansoura University, Mansoura, Egypt; ${ }^{2}$ Karl-Landsteiner-Institute for Lung Research and \\ Pulmonary Oncology, Vienna, Austria \\ Contributions: (I) Conception and design: All authors; (II) Administrative support: None; (III) Provision of study materials or patients: All authors; \\ (IV) Collection and assembly of data: All authors; (V) Data analysis and interpretation: All authors; (VI) Manuscript writing: All authors; (VII) Final \\ approval of manuscript: All authors. \\ Correspondence to: Dr. Mostafa Bakeer. Chest Medicine Department, Faculty of Medicine, Mansoura University, 35516 Mansoura, Egypt. \\ Email: mbekeer10@hotmail.com.
}

\begin{abstract}
Chronic obstructive pulmonary disease (COPD) is a heterogeneous disease associated with significant morbidity and mortality. Over the past few years, there has been cumulating interest in describing this heterogeneity and using this information to group patients into different COPD phenotypes. The term phenotype is defined as single or combination of disease attributes that describe differences between individuals with COPD as they relate to clinically meaningful outcomes. It describes also the physical appearance or biochemical characteristics which result from the genotype-environment interaction. Furthermore, it clearly identifies subgroups with a significant impact in the prognosis. Recently, approaches to COPD phenotyping have been significantly enhanced in tandem with developments in understanding the disease's various pathological, clinical and genetic features. This knowledge inspired the researchers to investigate more tailored therapeutic strategies that could not only give a more potent effect but also help to avoid the traditional therapy's undesirable side effects. Eventually, it could be said that the phenotypic approach to COPD in the last decade had a huge impact on daily practice and management delivered to COPD patients. In this review, we highlight the impact of pharmacological and non-pharmacological treatment options on COPD outcomes, using a personalized treatment strategy based on different phenotypes.
\end{abstract}

Keywords: Chronic obstructive pulmonary disease (COPD); phenotypes; therapeutics

Submitted Mar 05, 2020. Accepted for publication Oct 22, 2020.

doi: 10.21037/atm-20-2219

View this article at: http://dx.doi.org/10.21037/atm-20-2219

\section{Introduction}

Chronic obstructive pulmonary disease (COPD) is defined as a common, preventable, and treatable disease that is characterized by persistent respiratory symptoms and airflow limitation that is due to airway and/or alveolar abnormalities, usually caused by significant exposure to noxious particles or gases and influenced by host factors including abnormal lung development (1). The diagnosis of COPD should be considered in any patient who has dyspnea, chronic cough and/or sputum production, and a history of exposure to risk factors for the disease. Spirometry is required to make the diagnosis, however there may be significant lung pathology (e.g., emphysema) in the absence of airflow limitation that needs further evaluation. Drawbacks of the current diagnostic criteria include the fact

\footnotetext{
$\wedge$ ORCID: 0000-0001-7673-3065.
} 
that they do not reflect the heterogeneous histopathological or pathophysiological background observed in COPD (2).

\section{Approaches to COPD phenotyping}

Over recent years, the term "phenotype" has been introduced to help clinicians better to identify different types of COPD subgroups. "Phenotype" refers to a set of observable characteristics with which individuals can be grouped. The purpose of such grouping is to define clusters of patients with common characteristics that relate to clinically meaningful outcomes such as symptoms, prognosis and response to therapies (3).

In 1955, the earliest phenotypic classification of COPD was introduced to classify patients into two groups based on physical examination, the "Pink Puffers" and the "Blue Bloaters" (4). As spirometry came into routine use it was recognized that chronic airflow obstruction could be seen in a variety of overlapping conditions, such as chronic bronchitis, emphysema and asthma (5).

In more recent years, "cluster analysis" has been performed in an attempt to better characterize patient groups with specific baseline features beyond classical disease characteristics, such as age, gender, body-massindex, and/or smoking exposure (6-12).

These groupings are constructed such that the degree of association is strong between members of the same cluster and weak between members of different clusters (6).

While some of these clusters may use a single-scale, others may use a multi-dimensional approach (13). For instance, a "whole-person scale" is based on clinical symptoms (e.g., chronic bronchitis). An "organ scale" is based on lung function or radiology, such as description of emphysema or bronchial wall thickening. Others, such as the "cell tissue scale" or a "genetic scale" use either biological samples or genetic mutational analysis. These approaches however, did not integrate information from other scales of COPD which is critical to improve understanding of the disease (2).

In 2012, the Spanish Society of Pulmonology and Thoracic Surgery published the first clinical guideline using a multi-dimensional based approach of phenotyping and phenotype-based tailored treatment in COPD. Four clinical phenotypes were introduced based on exacerbation frequency and dominant clinical manifestations: non-exacerbators, asthma-COPD overlap (ACO), exacerbators with emphysema, and exacerbators with chronic bronchitis (14).
Using a cross-sectional Spanish cohort of patients with COPD, Miravitlles and co-workers (15) demonstrated that non-exacerbators were the most prevalent phenotype, comprising about two-third of the overall patient population studied. Since then, the Spanish classification has also been adopted by others. The POPE study $(16,17)$, a cohort of 3,362 patients from Central and Eastern Europe, confirmed the high prevalence of nonexacerbators found in the Spanish cohort, but also observed differences in the prevalence of these phenotypes between countries. Furthermore, exacerbators with or without chronic bronchitis had a higher symptom load and more frequent comorbidities compared to other phenotypes of interest. Both above-mentioned reports were further able to demonstrate that patients with COPD appear to receive inhaler treatment independent of their predominant clinical phenotype.

In the following section, we will review some of the evidence regarding phenotype-based treatment strategies. In addition to the conventional therapeutic options we also provide an overview of evolving, mainly endoscopic treatment approaches in selected patient groups and their impact on clinical course and outcomes. General recommendations, such as smoking cessation, vaccination, pulmonary rehabilitation, and identification and treatment of comorbidities should be applied to every patient with COPD, regardless of the phenotype, and thus will not be discussed here. We further acknowledge that there may be an overlap between phenotypes, thus therapeutic strategies mentioned below may be directed towards the predominant phenotype in individual patients. Strategies of the phenotype-based treatment of COPD are summarized in Table 1.

\section{Phenotype-based conventional management of COPD}

\section{Non-exacerbator phenotype}

By definition, these patients are characterized by presenting a maximum of one episode of moderate exacerbation in the previous year. In large COPD cohorts this is the most frequent COPD phenotype and comprises about two-thirds $(60 \%)$ of patients with COPD $(15,16)$.

Non-exacerbators have a lower risk of deterioration in quality of life, loss of lung function and mortality compared with the exacerbator phenotype (18). The majority of COPD patients with this phenotype remain in the same phenotype after 1 year follow up (19). The main focus of treatment is thus to ensure clinical stability by providing 
Table 1 Phenotype-based management of COPD

\begin{tabular}{|c|c|c|c|c|}
\hline Management & Non exacerbator & ACO & Emphysema exacerbator & Chronic bronchitis exacerbator \\
\hline \multirow{3}{*}{ General measures } & \multicolumn{4}{|l|}{ Smoking cessation } \\
\hline & \multicolumn{4}{|c|}{ Pulmonary rehabilitation } \\
\hline & \multicolumn{4}{|c|}{ Treatment of comorbidities } \\
\hline \multirow{2}{*}{ Pharmacological } & - & Anti-lgE & Mucolytics & Mucolytics \\
\hline & - & Anti-IL 5 & - & Macrolide therapy \\
\hline \multirow[t]{2}{*}{ Non pharmacological } & - & BT & LVRS & Mechanical mucus clearance \\
\hline & - & - & ELVR & TLD (experimental) \\
\hline
\end{tabular}

COPD, chronic obstructive pulmonary disease; ACO, asthma-COPD overlap; BD, bronchodilator; ICS, inhaled corticosteroid; LABA, long-acting 32 -agonist; LAMA, long-acting muscarinic antagonist; PDE-4, phosphodiesterase-4; BT, bronchial thermoplasty; LVRS, lung volume reduction surgery; ELVR, endoscopic lung volume reduction; TLD, targeted lung denervation.

appropriate inhaler therapy. Depending whether or not patients with COPD present with a high or low symptom load, mono or dual bronchodilator (BD) treatment should be the initial treatment and inhaled corticosteroid (ICS) treatment should be rather avoided in the absence of concomitant asthma $(1,20)$. Long-acting bronchodilators (LABD) are required in the majority of symptomatic patients. They enable better control of symptoms, and improve lung function $(21,22)$ in addition to reducing number of exacerbations (23). As mentioned above, nonpharmacological management should involve smoking cessation counseling, self-management, and rehabilitation efforts.

\section{Emphysema exacerbator phenotype}

This phenotype represents a smaller proportion of COPD patients with less than a $10 \%$ prevalence rate $(15,16)$. An exacerbator phenotype is defined as any patient with COPD who presents two or more moderate exacerbations (that require at least outpatient treatment with systemic corticosteroids and/or antibiotics) in the previous year, or at least one severe exacerbation that requires hospital admission (24). In order to differentiate a new event from a treatment failure, an acute episode either 4-6 weeks from the beginning of an original exacerbation or 4 weeks after the completion of its treatment is suggested as a definition for "recurrence" of COPD exacerbation (25).

Patients with an emphysema exacerbator phenotype demonstrate the highest mortality rate compared with other COPD phenotypes $(19,26)$. Due to the differential management, it is important to differentiate exacerbator patients with predominant emphysema from those with predominant symptoms of chronic bronchitis. In contrast to patients with chronic bronchitis, the emphysema phenotype appears to be experiencing exacerbations mainly due to hyperinflation rather than infection or inflammation. Identification of emphysema should be facilitated by measurement of gas trapping using static lung volumes and carbon monoxide diffusing capacity (DLCO) testing. In clinical routine, chest computed tomography $(\mathrm{CT})$ is the diagnostic approach of choice, and may be used for treatment selection in advanced disease (27).

In line with other recommendations we suggest that the first line therapy of the emphysema phenotype should be dual BD treatment (18).

Given the risk of pneumonia and the absence of relevant airway inflammation in these patients, ICS treatment should be rather avoided and reserved for patients with a history of asthma, atopy, and/or blood eosinophilia (measured during stable state) (28). In our clinical experience patients with predominant emphysema rather rarely fulfill these criteria, but about one-third of patients may also have a relevant component of overlapping chronic bronchitis and bronchiectasis, more frequently found in lower lobes. These patients are usually characterized by chronic cough and sputum production, and may depict mucus in central and 
peripheral airways and airway wall thickening on CT scans. Anti-inflammatory treatments may be an individual option in these patients as mentioned in the section on chronic bronchitis.

\section{Chronic bronchitis exacerbator phenotype}

Chronic bronchitis is determined by the presence of cough and sputum production for at least 3 months per year in 2 consecutive years (18). The prevalence rate of this phenotype was found in approximately $20 \%$ of COPD patients $(15,16)$.

Similar to the emphysema phenotype, patients with the chronic bronchitis are at an overall higher risk of moderate and severe exacerbations (19) in addition to worse respiratory symptoms (29). Patients with chronic bronchitis may undergo a high-resolution CT to rule out relevant bronchiectasis (30) and sputum cultures for identification of chronic microbial infection (31).

\section{Pharmacological management}

Similar to patients with emphysema, patients with a chronic bronchitic phenotype should also receive dual BD inhaler therapy. These patients, however, may further benefit from ICS (given above-mentioned criteria), and/or adding phosphodiesterase-4 (PDE-4) inhibitors (roflumilast) to inhaler therapy (32-34).

High-risk patients who had at least three exacerbations in the previous year and severe airflow obstruction despite adequate inhaler therapy may also be eligible for long-term treatment with macrolide antibiotics to reduce the number of exacerbations (35-37).

Similar to the use of macrolide antibiotics, data from randomized controlled trials may suggest the use of high dose mucolytics (e.g., $\mathrm{N}$-acetylcysteine, $600 \mathrm{mg}$ twice daily). Recent data suggests their benefits in reducing the number of exacerbations in high-risk patients, i.e., those with forced expiratory volume in 1 second $\left(\mathrm{FEV}_{1}\right)<50 \%$ or with two or more exacerbations in the previous year, or both $(38,39)$.

\section{Mechanical mucus clearance}

Patients with chronic bronchitis and bronchiectasis may also benefit from mechanical methods of mucus clearance, such as positive expiratory pressure, flutter valves, or high frequency chest compression vests; however, the evidence from these techniques usually do not stem from large, randomized clinical trials and thus should be applied critically (40). Similarly, other studies of chest physiotherapy or directed coughing techniques in COPD have shown some improvements in mucus clearance, but no changes in lung function (41).

\section{ACO phenotype}

ACO phenotype can be diagnosed in a patient with COPD who also meet the diagnostic criteria for asthma or who present features considered as suggestive of asthma, such as: a strongly positive BD test (increase in $\mathrm{FEV}_{1}>400 \mathrm{~mL}$ and $15 \%$ ), a history of atopy, and/or peripheral blood eosinophilia $>300$ cells per $\mathrm{mm}^{3}(14,42)$.

The reported prevalence of ACO greatly varies from $2 \%$ in a general population over 40 years of age, $11 \%$ to $56 \%$ among patients previously diagnosed with COPD and $13 \%$ to $61 \%$ among patients previously diagnosed with asthma (43). Epidemiologically, ACO patients have a female predominance, and affected patients appear to be younger compared to more "classic" COPD patients $(44,45)$. Clinically, ACO exacerbations do not usually present with purulent sputum, but rather with symptoms of rhinitis, wheezing and cough with whitish sputum (46,47). The treatment of ACO consists of adding ICS to BD treatment, given an underlying high degree of bronchial eosinophilic inflammation with a subsequent marked clinical and spirometric response $(48,49)$. Traditionally, ICS has been added to long-acting beta-agonist therapy, but more recently single-inhaler triple therapy with longacting muscarinic antagonist (LAMA), may offer a step-up approach in more severe cases (50).

Patients with frequent exacerbations despite regular inhaler therapy may also be candidates for anti-IgE antibody treatment with biologicals, such as anti-IgE or anti-IL 5 (51). Previous studies have shown improvements in pulmonary function tests, decreased levels of fractional exhaled nitric oxide (FeNO), eosinophils, neutrophils, and interleukin-4 with the use of omalizumab (52). Studies also have showed its efficacy in decreasing rates of exacerbation and hospitalizations as well as improved asthma control and health-related quality of life $(53,54)$.

\section{Phenotype-based interventional treatment options for COPD}

\section{Lung volume reduction procedures}

Given that lung hyperinflation is the driving component of symptoms and exercise limitation in patients with emphysema phenotype, lung volume reduction procedures in advanced disease may offer relieve. The landmark National Emphysema Treatment Trial (NETT) reported that lung volume reduction surgery (LVRS) in carefully selected patients with upper lobe predominant emphysema, led to durable improvement in exercise capacity, symptoms, 
and oxygen use (55). However due to the associated risks and costs, LVRS it is not commonly offered (56). More recently, endoscopic approaches to lung volume reduction have been adopted by the clinical community.

In fact, patients with emphysema phenotype may experience improvements in clinical outcomes (dyspnea score, exercise capacity and lung function) by endoscopic lung volume reduction (ELVR) using endobronchial valves, coils and thermal vapor ablation (57-60). Compared with surgical lung volume reduction, endoscopic treatment may also be applicable to patients with lower lobe emphysema. In fact, Eberhardt et al. were able to demonstrate similar improvements in clinical and functional outcomes following endobronchial valve therapy in upper versus lower lobe emphysema (61).

In addition to emphysema distribution, disease heterogeneity might also play a role in treatment selection. Heterogeneity is the relative difference in the emphysema scores between ipsilateral lobes. Heterogenous emphysema is generally defined as more than a $10 \%$ to $20 \%$ difference in the proportion of emphysema measured at $-910 \mathrm{HUs}$ or a $>10 \%$ difference in the proportion of pixels of less than $-950 \mathrm{HU}$ (62). While treatment with endobronchial valves has also been successfully performed in patients with homogenous emphysema (63), data from randomized controlled trials using other techniques such as coil treatment or vapor ablation have yet to confirm clinically meaningful efficacy in homogenous emphysema.

\section{Targeted lung denervation (TLD)}

Since a large subset of patients with bronchitic COPD remain symptomatic and continue to experience frequent exacerbations and symptoms despite optimal medical treatment, novel endoscopic approaches may apply to this patient group.

TLD has been developed with the intention of disruption of the peribronchial vagal innervation of the lungs and its downstream effects on mucus hypersecretion, bronchoconstriction, and airway hyperresponsiveness. While previous studies of TLD in COPD have predominantly focused on proof of concept, optimal dosing, an extended safety profiling $(64,65)$, the most recent AIRFLOW-2 trial prospectively evaluated the safety of this intervention, with the effect on respiratory adverse events as the primary outcome, in patients with symptomatic moderate to severe COPD (66). The authors of this report were able to demonstrate that TLD on top of maintenance inhaler therapy was associated with fewer respiratory adverse events in the primary endpoint time window and hospitalization for COPD exacerbations over 1 year of follow-up compared with control patients who underwent a sham procedure. The ongoing AIRFLOW-3 trial is a randomized controlled trial of TLD vs. sham with COPD exacerbation rates as a primary outcome.

\section{Bronchial rheoplasty}

Another endoscopic technology that may apply to chronic bronchitis patients is bronchial rheoplasty. It is a novel procedure in which pulsed electric fields are delivered to the airways via an endobronchial catheter, with the intention of ablation of mucus producing airway cells. First-in-man results from a recent multi-center study confirm safety and initial clinical outcomes of bronchial rheoplasty (67). In fact, treated patients had a substantial improvement in COPD symptoms, which were accompanied by changes in airway histology, i.e., a reduction in the number of mucusproducing cells.

\section{Bronchial thermoplasty (BT)}

BT is an approved technique that involves the application of high radiofrequency energy through a fiberoptic bronchoscopic catheter approach to selectively ablate airway smooth muscle in the proximal airways. BT has only been studied in severe asthma and the results showed a significant improvement in asthma control and quality of life in addition to reduction in the numbers of severe exacerbations, and the needed dose of oral corticosteroids $(68,69)$.

While patients with an explicit diagnosis of ACO have yet not been studied systematically (51), the underlying pathobiology and first case reports appear to underline the potential of BT in this patient group (70-72).

\section{Conclusions}

The application of the concept of phenotyping has resulted in a more individualized treatment approach in patients with COPD and appears to be increasingly adopted by guidelines and the clinical community.

\section{Acknowledgments}

Funding: None.

\section{Footnote}

Provenance and Peer Review: This article was commissioned 
by the Guest Editor (Bassam Redwan) for the series "Lung Emphysema" published in Annals of Translational Medicine. The article has undergone external peer review.

Conflicts of Interest: All authors have completed the ICMJE uniform disclosure form (available at http:// dx.doi.org/10.21037/atm-20-2219). The series "Lung Emphysema" was commissioned by the editorial office without any funding or sponsorship. Dr. GCF reports grants and personal fees from Boehringer Ingelheim, personal fees from Astra Zeneca, grants from Menarini, outside the submitted work. Dr. AV reports personal fees from Astra Zeneca, grants, personal fees and non-financial support from Boehringer Ingelheim, personal fees from Chiesi, personal fees from Menarini, personal fees from Novartis, outside the submitted work. The authors have no other conflicts of interest to declare.

Ethical Statement: The authors are accountable for all aspects of the work in ensuring that questions related to the accuracy or integrity of any part of the work are appropriately investigated and resolved.

Open Access Statement: This is an Open Access article distributed in accordance with the Creative Commons Attribution-NonCommercial-NoDerivs 4.0 International License (CC BY-NC-ND 4.0), which permits the noncommercial replication and distribution of the article with the strict proviso that no changes or edits are made and the original work is properly cited (including links to both the formal publication through the relevant DOI and the license). See: https://creativecommons.org/licenses/by-nc-nd/4.0/.

\section{References}

1. Global Strategy for the Diagnosis, Management and Prevention of COPD, Global Initiative for Chronic Obstructive Lung Disease (GOLD): 2020 report. Available online: http://www.goldcopd.org/ (Accessed: November, 2019).

2. Barker BL, Brightling CE. Phenotyping the heterogeneity of chronic obstructive pulmonary disease. Clin Sci (Lond) 2013;124:371-87.

3. Manian P. Chronic obstructive pulmonary disease classification, phenotypes and risk assessment. J Thorac Dis 2019;11:S1761-6.

4. Dornhorst AC. Respiratory insufficiency. Lancet 1955;268:1185-7.
5. Snider GL. Chronic obstructive pulmonary disease: a definition and implications of structural determinants of airflow obstruction for epidemiology. Am Rev Respir Dis 1989;140:S3-8.

6. Wardlaw AJ, Silverman M, Siva R, et al. Multi-dimensional phenotyping: towards a new taxonomy for airway disease. Clin Exp Allergy 2005;35:1254-62.

7. Moore WC, Meyers DA, Wenzel SE, et al. Identification of asthma phenotypes using cluster analysis in the severe asthma research program. Am J Respir Crit Care Med 2010;181:315-23.

8. Weatherall M, Travers J, Shirtcliffe PM, et al. Distinct clinical phenotypes of airways disease defined by cluster analysis. Eur Respir J 2009;34:812-8.

9. Haldar P, Pavord ID, Shaw DE, et al. Cluster analysis and clinical asthma phenotypes. Am J Respir Crit Care Med 2008;178:218-24.

10. Burgel PR, Paillasseur JL, Caillaud D, et al. Clinical COPD phenotypes: a novel approach using principal component and cluster analyses. Eur Respir J 2010;36:531-9.

11. Everitt R. An R and S-Plus Companion to Multivariate Analysis. London: Springer-Verlag, 2005.

12. McLachlan GJ. Cluster analysis and related techniques in medical research. Stat Methods Med Res 1992;1:27-48.

13. Antonelli Incalzi R, Canonica GW, Scichilone N, et al. The COPD multi-dimensional phenotype: a new classification from the STORICO Italian observational study. PLoS One 2019;14:e0221889.

14. Miravitlles M, Soler-Cataluña JJ, Calle M, et al. Spanish COPD guidelines (GesEPOC): pharmacological treatment of stable COPD. Spanish Society of Pulmonology and Thoracic Surgery. Arch Bronconeumol 2012;48:247-57.

15. Miravitlles $M$, Barrecheguren $M$, Román-Rodríguez $M$. Frequency and characteristics of different clinical phenotypes of chronic obstructive pulmonary disease. Int J Tuberc Lung Dis 2015;19:992-8.

16. Koblizek V, Milenkovic B, Barczyk A, et al. Phenotypes of COPD patients with a smoking history in Central and Eastern Europe: the POPE Study. Eur Respir J 2017;49:1601446.

17. Zbozinkova Z, Barczyk A, Tkacova R, et al. POPE study: rationale and methodology of a study to phenotype patients with COPD in Central and Eastern Europe. Int J Chron Obstruct Pulmon Dis 2016;11:611-22.

18. Miravitlles M, Soler-Cataluña JJ, Calle M, et al. Spanish 
Guidelines for Management of Chronic Obstructive Pulmonary Disease (GesEPOC) 2017. Pharmacological Treatment of Stable Phase. Arch Bronconeumol 2017;53:324-35.

19. Cosio BG, Soriano JB, López-Campos JL, et al. Distribution and outcomes of a phenotype-based approach to guide COPD management: results from the CHAIN Cohort. PLoS One 2016;11:e0160770.

20. Ariel A, Altraja A, Belevskiy A, et al. Inhaled therapies in patients with moderate $\mathrm{COPD}$ in clinical practice: current thinking. Int J Chron Obstruct Pulmon Dis 2017;13:45-56.

21. Tashkin DP, Cooper CB. The role of long-acting bronchodilators in the management of stable COPD. Chest 2004;125:249-59.

22. Stockley RA, Whitehead PJ, Williams MK. Improved outcomes in patients with chronic obstructive pulmonary disease treated with salmeterol compared with placebo/ usual therapy: results of a meta-analysis. Respir Res 2006;7:147.

23. Puhan MA, Bachmann LM, Kleijnen J, et al. Inhaled drugs to reduce exacerbations in patients with chronic obstructive pulmonary disease: a network meta-analysis. BMC Med 2009;7:2.

24. Hurst JR, Vestbo J, Anzueto A, et al. Susceptibility to exacerbation in chronic obstructive pulmonary disease. $\mathrm{N}$ Engl J Med 2010;363:1128-38.

25. Soler-Cataluña JJ, Rodriguez-Roisin R. Frequent chronic obstructive pulmonary disease exacerbators: how much real, how much fictitious? COPD 2010;7:276-84.

26. Golpe R, Suárez-Valor M, Martín-Robles I, et al. Mortality in COPD patients according to clinical phenotypes. Int J Chron Obstruct Pulmon Dis 2018;13:1433-9.

27. Labaki WW, Martinez CH, Martinez FJ, et al. The role of chest computed tomography in the evaluation and management of the patient with chronic obstructive pulmonary disease. Am J Respir Crit Care Med 2017;196:1372-9.

28. Agusti A, Fabbri LM, Singh D, et al. Inhaled corticosteroids in COPD: friend or foe? Eur Respir J 2018;52:1801219.

29. Kim V, Han MK, Vance GB, et al. The chronic bronchitic phenotype of COPD: an analysis of the COPDGene Study. Chest 2011;140:626-33.

30. Martínez-García MÁ, Soler-Cataluña JJ, Donat Sanz Y, et al. Factors associated with bronchiectasis in patients with COPD. Chest 2011;140:1130-7.

31. Miravitlles M, Marín A, Monsó E, et al. Colour of sputum is a marker for bacterial colonisation in chronic obstructive pulmonary disease. Respir Res 2010;11:58.

32. Martinez FJ, Rabe KF, Sethi S, et al. Effect of Roflumilast and Inhaled Corticosteroid/Long-Acting $\beta 2$-Agonist on Chronic Obstructive Pulmonary Disease Exacerbations (RE(2)SPOND). A Randomized Clinical Trial. Am J Respir Crit Care Med 2016;194:559-67.

33. Fabbri LM, Calverley PMA, Izquierdo-Alonso JL, et al. Roflumilast in moderate-to-severe chronic obstructive pulmonary disease treated with long acting bronchodilators: two randomised clinical trials. Lancet 2009;374:695-703.

34. Bateman ED, Rabe KF, Calverley PMA, et al. Roflumilast with long-acting b2-agonists for COPD: influence of exacerbation history. Eur Respir J 2011;38:553-60.

35. Uzun S, Djamin RS, Kluytmans JA, et al. Azithromycin maintenance treatment in patients with frequent exacerbations of chronic obstructive pulmonary disease (COLUMBUS): a randomised, doubleblind, placebocontrolled trial. Lancet Respir Med 2014;2:361-8.

36. Miravitlles M, Anzueto A. Antibiotic prophylaxis in COPD: why, when, and for whom? Pulm Pharmacol Ther 2015;32:119-23.

37. Ni W, Shao X, Cai X, et al. Prophylactic use of macrolide antibiotics for the prevention of chronic obstructive pulmonary disease exacerbation: a meta-analysis. PLoS One 2015;10:e0121257.

38. Tse HN, Raiteri L, Wong KY, et al. Benefits of highdose $\mathrm{N}$-acetylcysteine to exacerbation-prone patients with COPD. Chest 2014;146:611-23.

39. Zheng JP, Wen FQ, Bai CX, et al. Twice daily Nacetylcysteine $600 \mathrm{mg}$ for exacerbations of chronic obstructive pulmonary disease (PANTHEON): a randomised, double-blind placebo-controlled trial. Lancet Respir Med 2014;2:187-94.

40. Ramos FL, Krahnke JS, Kim V. Clinical issues of mucus accumulation in COPD. Int J Chron Obstruct Pulmon Dis 2014;9:139-50.

41. van der Schans CP. Conventional chest physical therapy for obstructive lung disease. Respir Care 2007;52:1198206; discussion 1206-9.

42. Miravitlles M, Alvarez-Gutierrez FJ, Calle M, et al. Algorithm for identification of asthma-COPD overlap: consensus between the Spanish COPD and asthma guidelines. Eur Respir J 2017;49:1700068.

43. Sin DD, Miravitlles M, Mannino DM, et al. What is asthma-COPD overlap syndrome? towards a consensus definition from a round table discussion. Eur Respir J 
2016;48:664-73.

44. Kumbhare S, Pleasants R, Ohar JA, et al. Characteristics and prevalence of asthma/chronic obstructive pulmonary disease overlap in the United States. Ann Am Thorac Soc 2016;13:803-10.

45. van Boven JF, Román-Rodriguez M, Palmer JF, et al. Comorbidome, pattern, and impact of asthma-COPD overlap syndrome in real life. Chest 2016;149:1011-20.

46. Bafadhel M, McKenna S, Terry S, et al. Acute exacerbations of chronic obstructive pulmonary disease: identification of biologic clusters and their biomarkers. Am J Respir Crit Care Med 2011;184:662-71.

47. Pavord ID, Lettis S, Locantore N, et al. Blood eosinophils and inhaled corticosteroid/long-acting $\beta$-2 agonist efficacy in COPD. Thorax 2016;71:118-25.

48. Barrecheguren M, Esquinas C, Miravitlles M. The asthmachronic obstructive pulmonary disease overlap syndrome (ACOS): opportunities and challenges. Curr Opin Pulm Med 2015;21:74-9.

49. Siva R, Green RH, Brightling CE, et al. Eosinophilic airway inflammation and exacerbations of COPD: a randomised controlled trial. Eur Respir J 2007;29:906-13.

50. Ishiura $Y$, Fujimura $M$, Ohkura $N$, et al. Effect of triple therapy in patients with asthma-COPD overlap. Int J Clin Pharmacol Ther 2019;57:384-92.

51. Barnes PJ. Therapeutic approaches to asthma-chronic obstructive pulmonary disease overlap syndromes. J Allergy Clin Immunol 2015;136:531-45.

52. Yalcin AD, Celik B, Yalcin AN. Omalizumab (anti$\mathrm{IgE}$ ) therapy in the asthma-COPD overlap syndrome (ACOS) and its effects on circulating cytokine levels. Immunopharmacol Immunotoxicol 2016;38:253-6.

53. Tat TS, Cilli A. Omalizumab treatment in asthma-COPD overlap syndrome. J Asthma 2016;53:1048-50.

54. Maltby S, Gibson PG, Powell H, et al. Omalizumab treatment response in a population with severe allergic asthma and overlapping COPD. Chest 2017;151:78-89.

55. Fishman A, Martinez F, Naunheim K, et al. A randomized trial comparing lung-volume-reduction surgery with medical therapy for severe emphysema. N Engl J Med 2003;348:2059-73.

56. van Agteren JE, Carson KV, Tiong LU, et al. Lung volume reduction surgery for diffuse emphysema. Cochrane Database Syst Rev 2016;10:CD001001.

57. Venuta F, Anile M, Diso D, et al. Long-term follow-up after bronchoscopic lung volume reduction in patients with emphysema. Eur Respir J 2012;39:1084-9.

58. Deslée G, Mal H, Dutau H, et al. Lung volume reduction coil treatment vs usual care in patients with severe emphysema: the REVOLENS Randomized Clinical Trial. JAMA 2016;315:175-84.

59. Sciurba FC, Chandra D, Bon J. Bronchoscopic lung volume reduction in COPD: lessons in implementing clinically based precision medicine. JAMA 2016;315:139-41.

60. Gompelmann D, Shah PL, Valipour A, et al. Bronchoscopic thermal vapor ablation: best practice recommendations from an expert panel on endoscopic lung volume reduction. Respiration 2018;95:392-400.

61. Eberhardt R, Herth FJ, Radhakrishnan S, et al. Comparing clinical outcomes in upper versus lower lobe endobronchial valve treatment in severe emphysema. Respiration 2015;90:314-20.

62. Herth FJ, Slebos DJ, Criner GJ, et al. Endoscopic lung volume reduction: an expert panel recommendation update 2019. Respiration 2019;97:548-57.

63. Valipour A, Slebos DJ, Herth F, et al. Endobronchial valve therapy in patients with homogeneous emphysema. results from the IMPACT study. Am J Respir Crit Care Med 2016;194:1073-82.

64. Valipour A, Asadi S, Pison C, et al. Long-term safety of bilateral targeted lung denervation in patients with COPD. Int J Chron Obstruct Pulmon Dis 2018;13:2163-72.

65. Valipour A, Shah PL, Pison C, et al. Safety and dose study of targeted lung denervation in moderate/severe COPD patients. Respiration 2019;98:329-39.

66. Slebos DJ, Shah PL, Herth FJF, et al. Safety and adverse events after targeted lung denervation for symptomatic moderate to severe chronic obstructive pulmonary disease (AIRFLOW). A multicenter randomized controlled clinical trial. Am J Respir Crit Care Med 2019;200:1477-86.

67. Valipour A, Fernandez-Bussy S, Ing AJ, et al. Bronchial Rheoplasty for Treatment of Chronic Bronchitis. TwelveMonth Results from a Multicenter Clinical Trial. Am J Respir Crit Care Med 2020;202:681-9.

68. Castro M, Rubin AS, Laviolette M, et al. Effectiveness and safety of bronchial thermoplasty in the treatment of severe asthma: a multicenter, randomized, double-blind, sham-controlled clinical trial. Am J Respir Crit Care Med 2010;181:116-24.

69. Pretolani M, Bergqvist A, Thabut G, et al. Effectiveness of bronchial thermoplasty in patients with severe refractory asthma: clinical and histopathologic correlations. J Allergy Clin Immunol 2017;139:1176-85.

70. Xia Y, Cao Y, Xia L, et al. Severe asthma and asthmaCOPD overlap: a double agent or identical twins? J 
Thorac Dis 2017;9:4798-805.

71. Hardin M, Cho M, McDonald ML, et al. The clinical and genetic features of COPD-asthma overlap syndrome. Eur Respir J 2014;44:341-50.

Cite this article as: Bakeer M, Funk GC, Valipour A. Chronic obstructive pulmonary disease phenotypes: imprint on pharmacological and non-pharmacological therapy. Ann Transl Med 2020;8(21):1472. doi: 10.21037/atm-20-2219
72. Sha J, Rorke S, Langton D. Airway smooth muscle as an underutilised biomarker: a case report. BMC Pulm Med 2019;19:24. 